\title{
Tingkat Bahaya Longsorlahan di Sub DAS Ngrancah Kabupaten Kulonprogo
}

\author{
Wildhan Dayu Hardhoni, Suratman, Djati Mardiatno
}

Masuk: 13012021 / Diterima: 20012021 / Dipublikasi: 30062021

\begin{abstract}
Indonesia is a country that has high disaster intensity, including natural disasters such as landslides. BNPB records note that during 2020, 573 landslides were recorded. In the Special Region of Yogyakarta Province, especially in Ngrancah sub-watershed, located in Kulon Progo Regency, several landslides have also occurred. Therefore, to minimize the incidence and losses due to landslides, it is necessary to conduct research that discusses the level of landslide hazards. This study aims to analyze the level of landslide hazard and the distribution of landslide hazard levels based on the zoning of the Ngrancah Sub-watershed. The data used are secondary data obtained from several government agencies, while the method for analysis uses overlapping between layer parameters and scoring for each parameter used. The results showed that there were three levels of danger spread in the Ngrancah Sub-watershed area, namely moderate (74 land units), high enough (380 land units), and high (155 land units). Meanwhile, the distribution of landslide hazard levels is quite high and high, mainly in the upper and middle stream areas. It is hoped that the results of this research will serve as a reference for all stakeholders in the management of the Ngrancah sub-watershed area following the capacity of the land itself.
\end{abstract}

Keywords: Landslide; Landslide Hazard Level; Subwatershed Area; Zoning

Abstrak Indonesia merupakan negara yang memiliki intensitas kebencanaan yang tergolong tinggi, termasuk bencana alam seperti longsorlahan. Dalam catatan BNPB diketahui bahwa selama tahun 2020 tercatat 573 kejadian longsorlahan. Pada wilayah Provinsi Daerah Istimewa Yogyakarta khususnya wilayah Sub DAS Ngrancah yang terletak di Kabupaten Kulon Progo juga terjadi beberapa kejadian longsorlahan. Oleh karena itu untuk meminimalisir kejadian maupun kerugian akibat longsorlahan perlu dilakukan penelitian yang membahas tentang tingkat bahaya longsorlahan. Penelitian ini memiliki tujuan yaitu menganalisis tingkat bahaya longsorlahan dan persebaran tingkat bahaya longsorlahan berdasarkan zonasi Sub DAS Ngrancah. Data yang digunakan adalah data skunder yang diperoleh dari beberapa instansi pemerintahan sedangkan metode untuk analisis menggunakan tumpeng tindih antar layer parameter dan skoring pada setiap parameter yang digunakan. Hasil penelitian menunjukkan bahwa terdapat tiga tingkat bahaya yang tersebar di wilayah Sub DAS Ngrancah yaitu sedang (74 satuan lahan), cukup tinggi (380 satuan lahan) dan tinggi (155 satuan lahan). Sedangkan persebaran tingkat bahaya longsorlahan cukup tinggi dan tinggi sebagian besar tersebar di wilayah zona hulu (upper stream) dan zona tengah (middle stream). Diharapkan hasil penelitian ini dijadikan sebagai salah satu referensi semua stakeholders dalam pengelolaan wilayah Sub DAS Ngrancah sesuai dengan kemampuan lahan itu sendiri.

Kata Kunci: Longsorlahan; Tingkat Bahaya Longsorlahan; Wilayah Sub DAS; Zonasi

This is an open access article under the CC BY-SA license.

Copyright (C) 2021 by Author. Published by Universitas Pendidikan Ganesha.

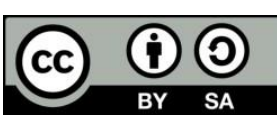

\section{Pendahuluan}

Indonesia merupakan negara yang memiliki intensitas kebencanaan

Wildhan Dayu Hardhoni, Suratman, Djati Mardiatno Universitas Gadjah Mada, Indonesia

wildhan.dayu@gmail.com yang tergolong tinggi, khususnya bencana hidrometeorologi seperti longsorlahan. Dalam catatan BNPB diketahui bahwa selama tahun 2020 tercatat 573 kejadian longsorlahan. 
Longsor adalah gerakan massa tanah dan batuan menuruni permukaan lereng yang miring (Zaruba, 1982; Meiarti, 2013). Longsorlahan merupakan bencana yang berpengaruh besar terhadap kehidupan serta keselamatan manusia. Longsorlahan merupakan bencana alam yang menjadi pusat perhatian dikarenakan bencana ini terjadi secara kontinyu dari tahun ke tahun, serta merupakan bencana alam yang paling banyak menimbulkan kerugian baik berupa materi maupun korban jiwa (Nusantara \& Setianto, 2015; Fadilah, 2019).

Sub DAS Ngrancah memiliki luasan 2110,02ha dan alirannya mengarah ke Waduk Sermo, sehingga Sub DAS Ngrancah merupakan catchment area Waduk Sermo yang menjadi elemen penting bagi kehidupan masyarakat di sekitarnya. Sub DAS Ngrancah meliputi dua desa yaitu Desa Hargowilis dan Desa Hargotirto, Kecamatan Kokap, Kabupaten Kulonprogo. Di wilayah Sub DAS Ngrancah kerap terjadi longsorlahan dan mengakibatkan sejumlah kerugian. Wilayah Sub DAS Ngrancah memiliki topografi yang tidak rata dan memiliki kemiringan lereng yang curam, hal ini diperparah dengan penggunaan lahan yang kurang tepat, seperti pada daerah yang lerengnya curam terdapat beberapa pemukiman dan terdapat ladang-ladang milik warga. Contoh kejadian longsorlahan yang terdapat di wilayah Sub DAS Ngrancah seperti yang ditampilkan pada Gambar 1.
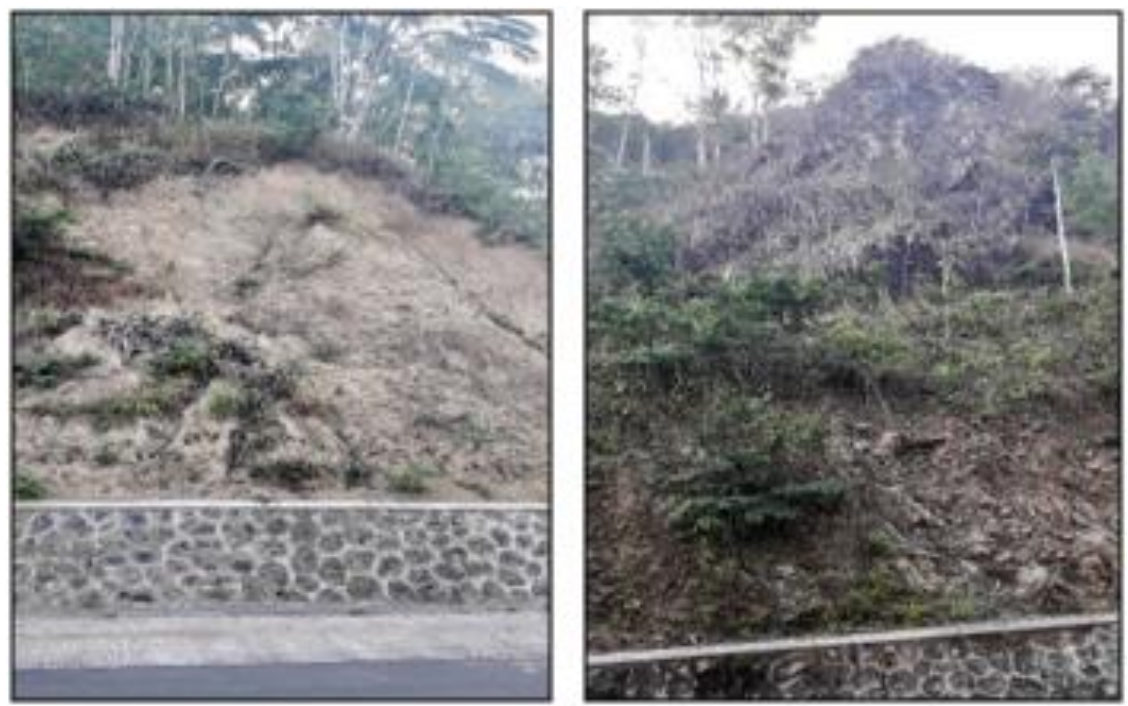

Gambar 1. Kejadian Longsorlahan di Sub DAS Ngrancah. (Sumber: Penulis, 2020)

Hal tersebut jelas sangat membahayakan dan memperbesar penyebab terjadinya longsorlahan. Longsorlahan dapat terjadi secara alamiah jika disebabkan oleh faktor-faktor alam dan dapat menimbulkan bencana jika merugikan manusia dari aspek sosial, ekonomi, dan lingkungan. Setiap daerah di Sub DAS Ngrancah memiliki karakteristik tipologi longsorlahan dan tingkat bahaya longsorlahan yang berbeda-beda. Hal tersebut dapat ditentukan dengan analisis frekuensi kejadian serta analisis sebaran longsorlahan yang terjadi di wilayah Sub DAS Ngrancah.

Pertambahan luas lahan kritis, erosi, banjir, sedimentasi dan tanah longsor merupakan indikator tentang menurunnya daya dukung DAS. Dilansir 
dari bpbd.kulonprogokab.go.id terdapat kenaikan kejadian longsorlahan seperti pada tahun 2018 yaitu 31 kejadian longsorlahan di Kecamatan Kokap menjadi 52 kejadian longsorlahan pada 2020. Kondisi DAS yang cenderung memburuk menyebabkan peristiwa erosi, banjir, sedimentasi dan tanah longsor akhir-akhir ini semakin sering terjadi dan cenderung meningkat. Untuk itu dibutuhkan penanganan yang menitikberatkan langsung pada masalahnya, agar kualitas suatu DAS dapat sesuai dengan harapan (Arsyad et al, 2018). Hal tersebut selaras dengan apa yang terjadi di wilayah penelitian jika dilihat dari catatan yang dikeluarkan oleh BPBD Kabupaten Kulon Progo pada tahun 2018 dan 2019 saja wilayah Kulon Progo mengalami kenaikan frekuensi kejadian longsorlahan dimana hal itu menunjukkan bahwa kondisi Sub DAS Ngrancah mengalami penurunan / bertambah buruk. Longsorlahan merupakan perpindahan material pembentuk lereng berupa batuan, bahan rombakan, tanah, atau material campuran tersebut, bergerak atau keluar lereng. Proses terjadinya longsorlahan diawali engan air yang meresap ke dalam tanah akan menambah bobot tanah. Jika air tersebut menembus sampai tanah kedap air yang berperan sebagai bidang gelincir, maka tanah menjadi licin dan tanah pelapukan di atasnya akan bergerak mengikuti lereng. ( Badan Geologi PVMBG Kementrian ESDM, 2017).

Longsorlahan terjadi bila gaya pendorong pada lereng lebih besar daripada gaya penahan. Gaya penahan umumnya dipengaruhi oleh kekuatan batuan dan kepadatan tanah. Sedangkan gaya pendorong dipengaruhi oleh besarnya sudut lereng, air, beban serta berat jenis tanah-batuan. Penyebab longsorlahan adalah lereng terjal, tanah yang kurang padat dan tebal, hujan, batuan yang kurang kuat, jenis penggunaan lahan, getaran, susut muka air danau atau bendungan, adanya beban tambahan, pengikisan/erosi, adanya material timbunan pada tebing, adanya bidang dikontinuitas, penggundulan hutan, daerah pembuangan sampah, dan pemotongan lereng (Badan Geologi PVMBG Kementrian ESDM,2017)

Erosi dan sedimentasi yang terjadi di wilayah Sub DAS Ngrancah berujung kepada meluasnya lahan kritis. Hal tersebut merupakan akibat dari eksploitasi sumberdaya alam yang melebihi daya dukung lahan yang ada, sehingga menimbulkan kerusakan sumberdaya alam dan berujung kepada timbulnya lahan-lahan kritis. Salah satu faktor penyebab timbulnya permasalahan-permasalahan tersebut adalah aktifitas manusia seperti penggunaan lahan seperti permukiman, fasilitas umum, jalan raya, ladang, kebun, dan lain-lain., serta aktiitas penggarapan lahan. Pada dasarnya manusia melakukan aktivitas untuk memenuhi berbagai kebutuhan dalam hidupnya. Aktivitas penduduk dalam mengelola lahan kurang memperhatikan kelestarian lingkungan sehingga menyebabkan terjadinya kecenderungan penurunan kualitas DAS (Suharno,1999; Kusumandari et al., 2012).

Pembuatan peta bahaya tanah longsor dengan menggunakan Sistem Informasi Geografis (SIG) mampu memberikan solusi dan kemudahan dalam analisis spasial secara berulang, kontinu, cepat dan akurat. Bahaya tanah longsor dapat diidentifikasi secara cepat melalui sistem informasi geografis dengan menggunakan metode tumpang susun atau overlay terhadap parameterparameter penyebab tanah longsor dan juga sangat penting dalam penanggulangan dan usaha mitigasi di wilayah yang rawan longsor, dikarenakan 
dapat digunakan untuk penyusunan sistem informasi penanggulangan bencana yang digunakan sebagai masukan bagi perencanaan dan pembangunan wilayah maupun penyempurnaan tataruang wilayah (Priyono et al, 2006). Implikasi penelitian ini menambahkan pernyatan Priyono, et al (2006) yaitu tidak hanya penyempurnaan tata ruang namun juga pengelolaan wilayah sesuai dengan daya dukung wilayah melalui tingkat bahaya longsorlahan wlayah penelitian.

Penelitian ini diharapkan dapat Memberikan referensi tambahan maupun masukan bagi pemerintah dalam membuat kebijakan dalam pengelolaan longsorlahan di wilayah Sub DAS Ngrancah. Memberikan saran atau masukan kepada pemerintah maupun semua pemangku kepentingan dalam hal penataan ruang dan rencana pembangunan agar penataan ruang dan rencana pembangunan khususnya di wilayah Sub DAS Ngrancah juga memperhatikan tentang kondisi fisik wilayah sehingga dapat meminimalisir risiko terjadinya bencana khususnya longsorlahan beserta segala kerugian yang akan ditimbulkan. Bahan untuk sosialisasi potensi bahaya longsorlahan sehingga masyarakat dapat mengetahui penyebab terjadinya longsorlahan serta dapat mengetahui tipologi lereng yang rawan terjadinya longsorlahan.

Penelitian sebelumnya sudah mengkaji beberapa permasalahan yang ada di Sub DAS Ngrancah seperti pengklasteran erosi, potensi erosi, analisis lahan kritis dan lain-lain. Namun belum ada yang melakukan analisis sebaran longsorlahan, tingkat bahaya dan persebaran tingkat bahaya longsorlahan berdasarkan zonasi Sub DAS Ngrancah. Untuk menangani hal tersebut perlu dilakukan riset ilmiah untuk mengkaji penyebab terjadinya longsorlahan di wilayah tersebut. Sangat perlu dilakukan penelitian tentang longsorlahan dengan menganalisis tingkat bahaya longsorlahan serta pembagian sebaran tingkat bahaya longsorlahan tersebut dengan zonasi Sub DAS agar dapat dijadikan salah satu referensi yang nantinya berguna untuk pembuatan strategi dalam pengelolaan wilayah Sub DAS Ngrancah dalam hal kebencanaan khususnya dalam hal longsorlahan. Tentu saja longsorlahan tidak hanya disebabkan oleh satu faktor namun beberapa faktor yang saling berkaitan di dalam suatu siklus ekosistem seperti halnya di wilayah Sub DAS Ngrancah. Jika dilihat dari relief permukaan, Sub DAS Ngrancah memiliki kemiringan lereng yang tinggi dikarenakan berada di kawasan Pegunungan Menoreh, sehingga bentuk permukaannya memiliki kemiringan lereng yang sebagian besar terjal. Penelitian ini bertujuan untuk menganalisis tingkat bahaya longsorlahan di Sub DAS Ngrancah dan persebaran tingkat bahaya longsorlahan berdasarkan zonasi di Sub DAS Ngrancah.

\section{Metode \\ Waktu dan Lokasi Penelitian}

Penelitian ini dimulai dilaksanakan pada Bulan Maret hingga Desember 2020 dengan melakukan pengumpulan data dari instansi pemerintahan lalu dilakukan dengan pengolahan data, analisis serta penyajian hasil analisis yang dilakukan.

\section{Alat dan Bahan Penelitian}

Alat yang digunakan dalam penelitian ini yaitu Laptop untuk mengoperasikan program-program yang digunakan analisis data seperti ArcMap 10.5 dan Quantum GIS 3.10

Bahan yang digunakan dalam penelitian ini yaitu Peta $\mathrm{RBI}$ skala 1:25.000 lembar Bagelen (1408-213) dan 
Wates (1408-214), Citra Satelit Resolusi Tinggi dengan resolusi spasial $4 \mathrm{~m}$ dan shp / shapefile yang didapatkan dari berbagai instansi pemerintahan seperti formasi batuan, kemiringan lereng, penggunaan lahan, jenis tanah, tekstur tanah dan kedalaman tanah.

\section{Teknik Pengumpulan Data}

Penelitian ini menggunakan data skunder yang diperoleh dari berbagai instansi pemerintahan sesuai dengan parameter-parameter dimana setiap parameter yan digunakan diberikan skor yang selanjutnya di olah dan di analisis yang menghasilkan beberapa peta yang menunjukkan tingkat bahaya longsorlahan. Referensi yang digunakan berasal dari jurnal, buku maupun penelitian lain.

\section{Teknik Analisis Data}

1) Analisis Tingkat Bahaya Longsorlahan

Untuk menganalisis tingkat bahaya longsorlahan dilakukan dengan penyusunan satuan lahan lalu dilakukan skoring, yaitu dengan memberikan pengharkatan dan pembobotan terhadap faktor penentu terjadinya longsorlahan. Satuan lahan ialah suatu area di permukaan bumi yang memiliki kualitas lahan dan karakteristik lahan yang khas, yang dapat ditentukan batasnya pada peta (Ismail, 2007; Fitria, 2009). Satuan lahan diperoleh dari overlay / tumpangsusun unsur batuan (Peta Formasi Batuan), unsur tanah (Peta Jenis Tanah), unsur penggunaan lahan (Peta Penggunaan Lahan) dan unsur topografi (Peta Kemiringan Lereng).

Setelah satuan lahan jadi selanjutnya dilakukan intersect dengan tekstur tanah dan kedalaman untuk keperluan pengharkatan atau scoring. Pelaksanaan pengharkatan tersebut dilakukan secara stratified/bertingkat dimana dimulai dengan harkat kecil (1) yang berarti memiliki pengaruh yang terkecil terhadap longsorlahan, hingga harkat besar (5). Penjelasan skor setiap parameter yang digunakan dijelaskan secara lengkap pada Tabel 1.

Tabel 1. Pengharkatan/Scoring

Parameter Tingkat Bahaya Longsorlahan

\begin{tabular}{|c|c|c|}
\hline Parameter dan Besaran & Kriteria & Skor \\
\hline Kemixingan Lereng (\%) & & \\
\hline 345 & Terial & 5 \\
\hline $25-45$ & Sangat. Curam & 4 \\
\hline $15-25$ & Curtam & 3 \\
\hline $8-15$ & AgakCuram & 2 \\
\hline 0.8 & Agak Datar & 1 \\
\hline $\begin{array}{c}\text { Teksotur Tanah } \\
\end{array}$ & & \\
\hline Telostur. lemposug bernasir. lempung debu, dan lempung & Halus & 5 \\
\hline Tekstur geluh lempungan, pasiran dan geluh lempung debuan & Agrok Halus & 4 \\
\hline 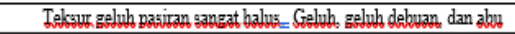 & Sedang & 3 \\
\hline Lelostur gelunh pasiran, dan geluh pasiram sangat balus & Agak Kasar & 2 \\
\hline Telogtur pasiran dan paris geluhaha & Kasas. & 1 \\
\hline Kedalaman Tanah $(\mathrm{cm})$ & & \\
\hline$>120$ & Sangat Dalam & 5 \\
\hline $90-120$ & Dalam & 4 \\
\hline $60-90$ & Sedang & 3 \\
\hline $50-60$ & Dangabal & 2 \\
\hline$<50$ & Sangat Dangabal & 1 \\
\hline Peuggunaan Lahana & & \\
\hline Savvah & & 5 \\
\hline Rermulimasna & & 4 \\
\hline Perkebunan & & 3 \\
\hline Tegalan/ladang dan semak & & 2 \\
\hline Hutan & & 1 \\
\hline
\end{tabular}

(Sumber: Hadmoko, et al. 2010 ; Penulis. 2020)

Untuk mengetahui tingkat bahaya longsorlahan dilakukan klasifikasi data untuk menentukan skor / harkat kelas bahaya longsorlahan dengan melakukan penentuan interval kelas, yaitu:

$\mathrm{Ki}=\frac{\mathrm{Xt}-\mathrm{Xr}}{\mathrm{K}} \quad \mathrm{Ki}=\frac{20-4}{4}=\frac{16}{4} \quad \mathrm{Ki}=4$

Keterangan:

$\mathrm{Ki}:$ Interval Kelas Longsorlahan

Xt : Jumlah Tertinggi dari harkat (20)

$\mathrm{Xr}$ : Jumlah Terendah dari harkat (4)

$\mathrm{K}$ : Jumlah Parameter Bahaya Longsorlahan (4)

Dengan demikian dapat dibuat klasifikasi tingkat bahaya longsorlahan Sub DAS Ngrancah seperti yang ditampilkan pada Tabel 2. 
Tabel 2. Klasifikasi Tingkat Bahaya Longsorlahan

\begin{tabular}{|c|c|c|c|}
\hline No & Klasifikasi & Skor & $\begin{array}{c}\text { Tingkat Bahaya } \\
\text { Longsorlahan }\end{array}$ \\
\hline 1 & I & $1-4$ & Rendah \\
\hline 2 & II & $5-8$ & Sedang \\
\hline 3 & III & $9-12$ & Cukup Tinggi \\
\hline 4 & IV & $13-16$ & Tinggi \\
\hline 5 & V & $17-20$ & Sangat Tinggi \\
\hline
\end{tabular}

2) Tingkat Bahaya Longsorlahan Berdasarkan Zonasi Sub DAS

Setelah melakukan analisis terhadap tingkat bahaya longsorlahan yang ada di wilayah Sub DAS Ngrancah pada tujuan penelitian sebelumnya, maka dilakukan pembatasan tingkat bahaya longsorlahan dengan zonasi dari Sub DAS Ngrancah itu sendiri. Pembagian zonasi Sub DAS dapat digambarkan dengan penjelasan pada Tabel 3.

Tabel 3. Zonasi Sub DAS

\begin{tabular}{|c|c|c|}
\hline No & Zonasi & Keterangan \\
\hline 1 & Hulu & $\begin{array}{l}\text { Topografi bergelombang, } \\
\text { kemiringan lereng tinggi, } \\
\text { berbukit atau bergunung, } \\
\text { sumber material erosi, aliran } \\
\text { arus deras, penampang } \\
\text { berbentuk V, batu-batuan } \\
\text { masih berukuran relatif besar } \\
\text { dan terdapat jeram atau air } \\
\text { terjun. }\end{array}$ \\
\hline 2 & Tengah & $\begin{array}{l}\text { Topografi relatif datar, } \\
\text { kalaupun ada perbukitan } \\
\text { atau bermofologi tidak rata } \\
\text { biasanya kemiringan lereng } \\
\text { tidak terlalu tinggi, tingkat } \\
\text { erosi relatif menengah - } \\
\text { rendah., kecepatan arus } \\
\text { aliran tidak terlalu deras, } \\
\text { biasanya terdapat meander } \\
\text { atau lengkungan sungai. }\end{array}$ \\
\hline 3 & Hilir & $\begin{array}{l}\text { Topografi relatif datar, } \\
\text { kemiringan lereng rendah, } \\
\text { tempat sedimentasi material } \\
\text { erosi dari zonasi di atasnya, } \\
\text { arus aliran relatif lambat dan } \\
\text { tenang. }\end{array}$ \\
\hline
\end{tabular}

(Sumber: Fadilah, et al. 2019)
Dalam membatasi setiap zonasi Sub DAS Ngrancah dilakukan digitasi. Hasil dari digitasi zona Sub DAS digambarkan pada Gambar 2.

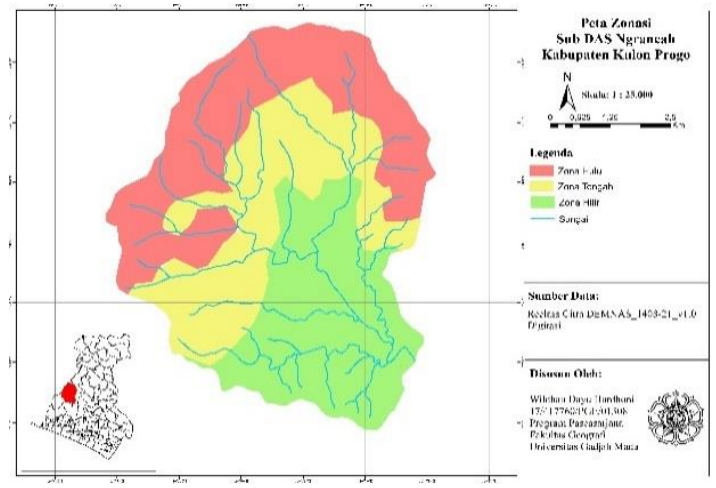

Gambar 2. Peta Zonasi Sub DAS Ngrancah

\section{Hasil dan Pembahasan}

\section{Analisis Tingkat Bahaya Longsorlahan}

Dari hasil intersect formasi batuan, jenis tanah, penggunaan lahan dan kemiringan lereng wilayah Sub DAS Ngrancah terdapat 609 satuan lahan dan ditampilkan pada Gambar 3.

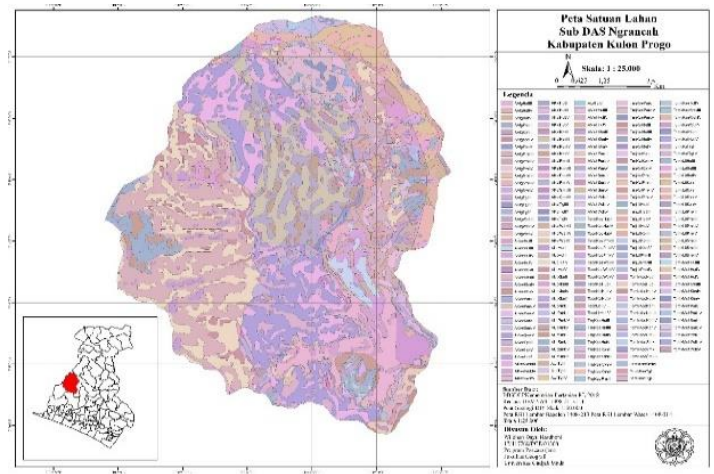

Gambar 3. Peta Satuan Lahan Sub DAS Ngrancah

Untuk parameter tingkat bahaya longsorlahan yang digunakan yaitu kemiringan lereng, tekstur tanah, kedalaman tanah dan penggunaan lahan. Setiap parameter tersebut diberikan nilai sesuai dengan Tabel 1 dan untuk klasifikasi tingkat bahaya longsorlahannya sesuai dengan Tabel 2.

Wilayah Sub DAS Ngrancah memiliki tiga tingkat bahaya longsorlahan sebagai berikut. 
Tingkat Bahaya Longsorlahan Klas II (Sedang) meliputi 74 Satuan Lahan dan digambarkan pada Gambar 4.

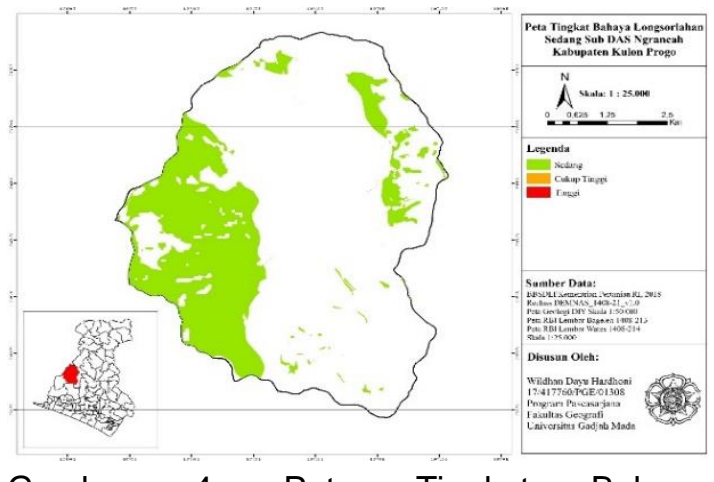

Gambar 4. Peta Tingkat Bahaya Longsorlahan Sedang Sub DAS Ngrancah

Tingkat Bahaya Longsorlahan Klas III (Cukup Tinggi) meliputi 380 Satuan Lahan dan digambarkan pada Gambar 5.

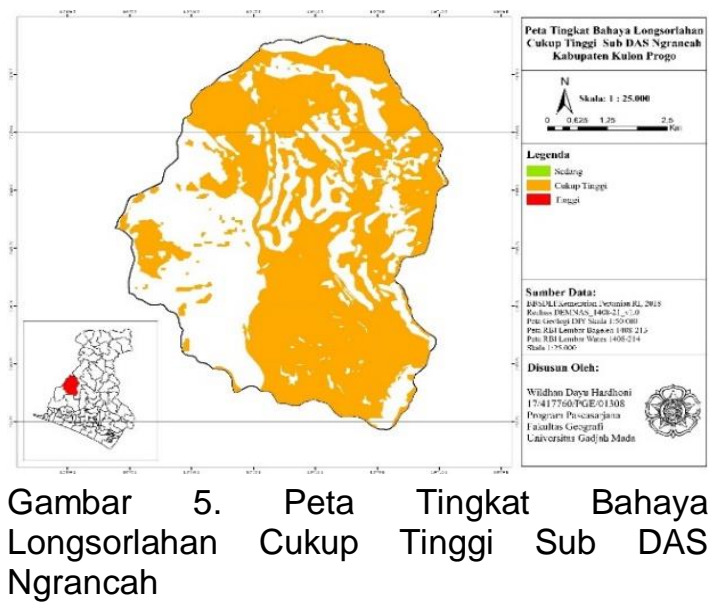

Tingkat Bahaya Longsorlahan Klas IV (Tinggi) meliputi 155 Satuan Lahan dan digambarkan pada Gambar 6.

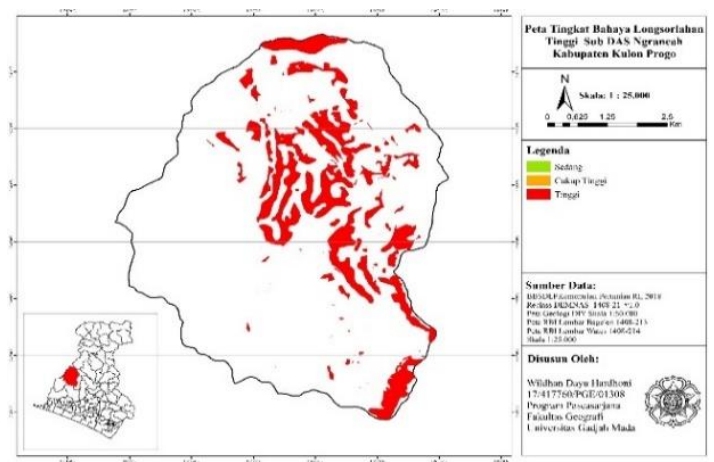

Gambar 6. Peta Tingkat Bahaya Longsorlahan Tinggi Sub DAS Ngrancah
Dalam penelitian Hadmoko, et al (2010) menyajikan tingkat bahaya longsorlahan dalam skala yang lebih besar yaitu Kabupaten, yang mana pada penelitian ini menggunakan skala yang lebih kecil yaitu Sub DAS dan hal tersebut menghasilkan paparan tingkat bahaya longsorlahan yang lebih detail. Oleh karena hal tersebut juga parameter yang digunakan juga berbeda dimana pada penelitian ini parameter curah hujan di eliminasi dikarenakan skala wlayah yang kecil sehingga memiliki curah hujan yang sama.

Berdasarkan analisis tingkat bahaya longsorlahan yang sudah dilakukan, wilayah Sub DAS Ngrancah di dominasi oleh tingkat bahaya Cukup Tinggi (III) dan yang paling sedikit adalah tingkat bahaya Rendah (I) dan Sangat Tinggi (V). Parameter-parameter yang digunakan sudah di jelaskan sebelumnya. Penjelasan lebih jelas akan dijabarkan pada Tabel 4.

Tabel 4. Perbandingan Sebaran Jumlah

Satuan Lahan Berdasarkan Tingkat Bahaya Longsorlahan Sub DAS Ngrancah

\begin{tabular}{|c|c|c|c|c|}
\hline No & $\begin{array}{c}\text { Tingkat } \\
\text { Bahaya }\end{array}$ & $\begin{array}{c}\text { Skor/ } \\
\text { Harkat }\end{array}$ & $\begin{array}{c}\text { Klasi } \\
\text { fikasi }\end{array}$ & $\begin{array}{c}\text { Jumla } \\
\mathbf{h} \\
\text { Satlah }\end{array}$ \\
\hline 1 & Rendah & $1-4$ & I & 0 \\
\hline 2 & Sedang & $5-8$ & II & 74 \\
\hline 3 & $\begin{array}{c}\text { Cukup } \\
\text { Tinggi }\end{array}$ & $9-12$ & III & 380 \\
\hline 4 & Tinggi & $13-16$ & IV & 155 \\
\hline 5 & $\begin{array}{c}\text { Sangat } \\
\text { Tinggi }\end{array}$ & $17-20$ & V & 0 \\
\hline & Jumlah & & & $\mathbf{6 0 9}$ \\
\hline
\end{tabular}

\section{Persebaran Tingkat Bahaya Longsorlahan Berdasarkan Zonasi Sub DAS Ngrancah}

Dasar pembuatan zonasi pada Sub DAS Ngrancah didasarkan pada referensi tabel 3. Penulis melakukan digitasi SHP / shapefile kemiringan lereng 
yang sebelumnya digunakan untuk pembuatan Peta Kemiringan Lereng, Peta Satuan Lahan dan Peta Tingkat Bahaya Longsorlahan. Digitasi dilakukan dengan membuat polygon yang membagi bagan-bagan tersebut. Proses digitasi dilakukan dengan pengamatan kenampakan wilayah penelitian yang setiap wilayahnya memiliki kemiringan lereng yang berbeda-beda. Penjelasan lebih lanjut mengenai Zonasi Sub DAS dijelaskan pada Tabel 5 .

Tabel 5. Zonasi Sub DAS

\begin{tabular}{|c|c|c|}
\hline No & Zona & Keterangan \\
\hline 1 & $\begin{array}{l}\text { Hulu } \\
\text { (Upper } \\
\text { Stream) }\end{array}$ & $\begin{array}{l}\text { Topografi bergelombang, } \\
\text { kemiringan lereng tinggi, } \\
\text { berbukit atau bergunung, } \\
\text { sumber material erosi, aliran } \\
\text { arus deras, penampang } \\
\text { berbentuk V, batu-batuan } \\
\text { masih berukuran relatif besar } \\
\text { dan terdapat jeram atau air } \\
\text { terjun. }\end{array}$ \\
\hline 2 & $\begin{array}{l}\text { Tengah } \\
\text { (Middle } \\
\text { Stream) }\end{array}$ & $\begin{array}{l}\text { Topografi tidak terlalu } \\
\text { bergelombang, kalaupun ada } \\
\text { perbukitan atau bermofologi } \\
\text { tidak rata biasanya } \\
\text { kemiringan lereng tidak } \\
\text { terlalu tinggi, tingkat erosi } \\
\text { relatif menengah - rendah., } \\
\text { penampang berbentuk U, } \\
\text { kecepatan arus aliran tidak } \\
\text { terlalu deras/menengah, } \\
\text { material erosi yang } \\
\text { mengendap hanya berjumlah } \\
\text { sedikit. }\end{array}$ \\
\hline 3 & $\begin{array}{c}\text { Hilir } \\
\text { (Lower } \\
\text { Stream) }\end{array}$ & 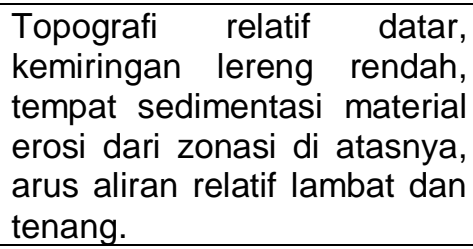 \\
\hline
\end{tabular}

(Sumber: Fadilah, et al. 2019)

Pembuatan zonasi hulu dibuat berdasarkan wilayah-wilayah yang memiliki kemiringan lereng tinggi dan memiliki topografi perbukitan. Zona tengah dibuat berdasarkan dari wilayah yang memiliki kemiringan lereng sedang dan topografinya tidak terlalu kasar serta zona hilir dibuat berdasarkan wilayah yang memiliki kemiringan lereng relatif datar, lalu hasil digitasi tersebut di overlay kan dengan SHP tingkat bahaya longsorlahan sehingga diketahui persebaran tingkat bahaya longsorlahan berdasarkan zonasinya. Hasil analisis persebaran tingkat bahaya longsorlahan berdasarkan zonasi ditampilkan pada Gambar 7.

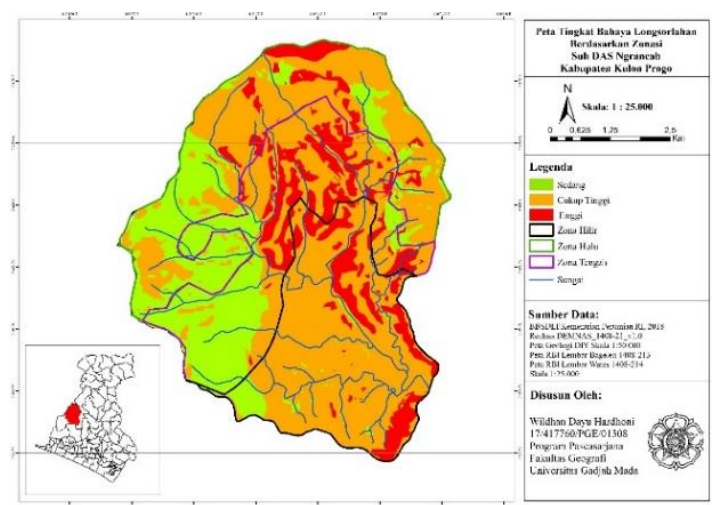

Gambar 7. Peta Persebaran Tingkat Bahaya Longsorlahan Berasarkan Zonasi Sub DAS Ngrancah

Berdasarkan Peta diatas, dapat di simpulkan sebagai berikut:

1) Zona Hulu (Upper Stream)

Tingkat bahaya longsorlahan cukup tinggi dominan berada dalam lingkup zona hulu Sub DAS Ngrancah. Pada zona hulu tersebut memiliki kemiringan lereng yang cenderung tinggi dikarenakan pada zona hulu di dominasi oleh perbukitan. Selain itu zona hulu juga memiliki arus aliran dan deras serta material erosi berasal dari zona hulu yang mana bisa disimpulkan jika zona hulu merupakan zona erosi utama dalam suatu DAS ataupun Sub DAS.

Selain kemiringan lereng, hal tersebut tentunya juga di pengaruhi oleh parameter-parameter yang lain yang menentukan tingkat bahaya longsorlahannya. Seperti penggunaan lahan yang ada di lingkup zona hulu di dominasi oleh kebun, hutan, semak dan 
pemukiman. Sudah diketahui jika hutan memiliki skor 1 menunjukkan pengaruhnya sedikit dalam tingkat bahaya longsorlahan. Namun terdapat pemukiman dan perkebunan yang memiliki skor 4 dan 3 yang mempengaruhi tingkat bahaya longsorlahan pada zona hulu. Hasil analisis persebaran tingkat bahaya longsorlahan pada zona hulu (upper stream) ditampilkan pada Gambar 8.

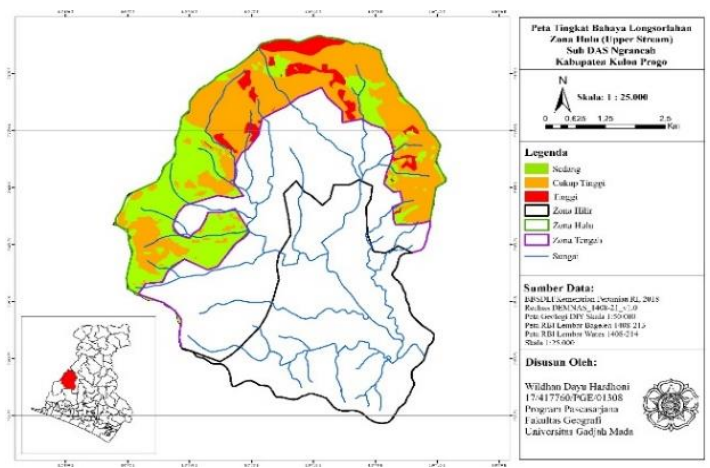

Gambar 8. Peta Persebaran Tingkat Bahaya Longsorlahan Pada Zona Hulu (upper stream) Sub DAS Ngrancah

\section{2) Zona Tengah (Middle Stream)}

Dalam lingkup zona tengah, tingkat bahaya longsorlahan sedang, cukup tinggi dan paling sedikit ialah rendah. Pada zona tengah memiliki kemiringan lereng yang tidak terlalu terjal seperti yang ada di zona hulu yang wilayahnya sebagian besar berupa perbukitan. Pada zona tengah terdapat beberapa bukit namun kemiringannya tidak sebesar zona hulu dan terdapat banyak wilayah yang memiliki kemiringan lereng agak datar dan agak curam.

Penggunaan lahan yang ada di zona tengah di dominasi oleh perkebunan dan hutan, dimana dua jenis penggunaan lahan ini memiliki pengaruh yang sedikit dan menengah dalam besarnya tingkat bahaya longsorlahan. Kedalaman tanah dalam, dangkal dan sangat dangkal juga memiliki komposisi yang hampir sama dalam zona tengah. asil analisis persebaran tingkat bahaya longsorlahan pada zona tengah (middle stream) ditampilkan pada Gambar 9.

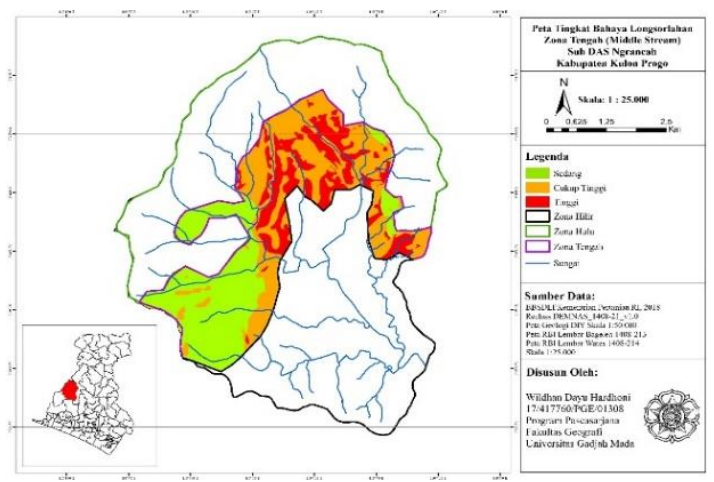

Gambar 9. Peta Persebaran Tingkat Bahaya Longsorlahan Pada Zona Tengah (middle stream) Sub DAS Ngrancah

\section{3) Zona Hilir (Lower Stream)}

Wilayah yang masuk dalam lingkup zona hilir memiliki persebaran tingkat bahaya longsorlahan cukup tinggi, tinggi dan sedikit bagian wilayah yang memiliki tingkat bahaya longsorlahan sedang Penggunaan lahan pada zona hilir variatif, dimana di dominasi oleh hutan yang memiliki pengaruh kecil terhadap tingkat bahaya longsorlahan. Terdapat juga Waduk Sermo yang menjadi penampung aliran air dari Sub DAS Ngrancah dan tempat sedimentasi material yang sebelumnya ter erosi di dua zona atasnya an juga terdapat pemukiman, kebun dan tegalan/ladang. asil analisis persebaran tingkat bahaya longsorlahan pada zona hilir (lower stream) ditampilkan pada Gambar 10.

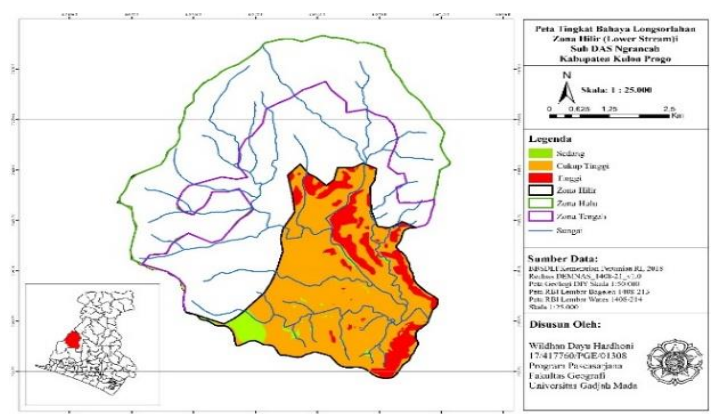

Gambar 10. Peta Persebaran Tingkat Bahaya Longsorlahan Pada Zona Hilir (lower stream) Sub DAS Ngrancah 
Berdasarkan pada analisis yang sudah dilakukan untuk mengetahui persebaran tingkat bahaya berdasarkan zonasi bisa disimpulkan jika wilayah Sub DAS Ngrancah memiliki tingkat bahaya longsorlahan yang merata dimana setiap zona memiliki tingkat bahaya yang hamper seimbang yaitu sedang, cukup tinggi dan tinggi. Hal ini dipengaruhi oleh parameter-parameter tingkat bahaya longsorlahan yang digunakan yaitu penggunaan lahan, kemiringan lereng, tekstur tanah dan kedalaman tanah. Hasil penelitian menunjukkan bahwa potensi longsorlahan di wilayah Sub DAS Ngrancah sangat memungkinkan terjadi, terutama pada wilayah zona hulu dan tengah. Hal tersebut menunjukkan bahwa zona hulu butuh perhatian lebih dan tingkat bahaya longsorlahan tersebut dapat menjadi salah satu tolak ukur untuk stakeholders dalam dalam pengolahan dan pengambilan keputusan oleh semua agar lingkungan tetap terjaga dan bencana longsorlahan dapat diminamilisir dampak, besaran dan kemungkinan kejadiannya.

\section{Penutup}

Berdasarkan hasil dan pembahasan penelitian, maka dapat disimpulkan bahwa Sub DAS Ngrancah memiliki empat kelas tingkat bahaya longsorlahan dari lima kategori tingkat bahaya yang ditentukan yaitu: (1) Tingkat Bahaya Longsorlahan Sedang (II) dengan skor 5 8 melingkupi 74 Satuan Lahan, (2) Tingkat Bahaya Longsorlahan Cukup Tinggi (III) dengan skor 9 - 12 melingkupi 380 Satuan Lahan dan (3) Tingkat Bahaya Longsorlahan Tinggi (IV) dengan skor 13 - 16 melingkupi 155 Satuan Lahan. Persebaran tingkat bahaya longsorlahan berdasarkan zonasi dapat disimpulkan bahwa zona hulu di dominasi oleh tingkat bahaya longsorlahan cukup tinggi, tinggi dan sedang. Hal tersebut dikarenakan zona hulu (upper stream) memiliki kemiringan lereng yang tinggi, morfologi yang tidak rata (di dominasi oleh perbukitan) dan parameterparameter lainnya. Zona tengah (middle stream) terdapat tingkat bahaya longsorlahan tinggi namun banyak juga wilayah yang memiliki tingkat bahaya longsorlahan cukup tinggi dan sedang. Sedangkan zona hilir (lower stream) di dominasi oleh tingkat bahaya longsorlahan cukup tinggi, tinggi dan sedikit terdapat tingkat bahaya longsorlahan rendah.

\section{Daftar Pustaka}

Arsyad, U: Barkey, R: Wahyuni: Matandung, K.K. 2018. Karakteristik Tanah Longsor di Daerah Aliran Sungai Tangka. Jurnal Hutan dan Masyarakat, 10(1).

Badan Geologi PVMBG. 2017. Buklet Gerakan Tanah. Kementrian Energi dan Sumber Daya Mineral. Bandung.

dibi.bnpb.go.id/DesInventar/main.js $\mathrm{p}$ ? countrycode=id\&lang=EN.

Diakses pada 19 Desember 2020, pukul 13.12

Fadilah, N: Arsyad, U: Soma, A.S. 2019. Analisis Tingkat Kerawanan Tanah Longsor Menggunakan Metode Frekuensi Rasio di Daerah Aliran Sungai Bialo. Jurnal Perennial, 15(2).

Fitria, N. 2009. Analisis tingkat bahaya longsor daerah aliran sungai (DAS) botok Kabupaten Karanganyar tahun 2009. Universitas Sebelas Maret, Surakarta.

Hadmoko. 2010. Landslide Hazard and Risk Assessment and Their Application in Risk Management and Landuse Planning in Eastern Flank of Menoreh Mountains, 
Yogyakarta Province, Indonesia. Springer.

Knight, J., Mitchell, W. A. 2011. Geomorpfological Field Mapping. In M. J. Smith, P. Paron, G. a. S., \& J. S. JR (Ed.), Geomorphological Mapping: Methods and Applications (Vol. 15, pp. 151-187). Elsevier.

Kusumandari, A, Marsono, D., Sabarnurdin, S., Gunawan, T. 2010. Pengkalsteran Erosi di Sub DAS Ngrancah, Kulonprogo. Jurnal Manusia dan Lingkungan, 19(1).

Lynn M., Highland, Bobrowsky, P. 2008. The Landslide Handbook-A Guide to Understanding Landslides. Geological Survey of Canada. USGS.

Priyono, K.D: Priyana, Y., Priyono. 2006. Analisis Tingkat Bahaya Longsor Tanah di Kecamatan Banjarmangu Kabupaten Banjarnegara. Forum Geografi, 20(2).

Meiarti, R. 2013. Analisis Pola Spasial Distribusi Longsor untuk Penentuan Faktor Pengontrol Utama Longsorlahan di DAS Kodil Jawa Tengah. Skripsi. Yogyakarta: Fakultas Geografi Universitas Gadjah Mada.

Van Zuidam, R.A., Van ZuidamCancelado, F.I. 1979. Terrain analysis and classification using aerial photographs. $A$ geomorphological approach. ITC Textbook of Photo-interpretation. ITC. Enschede. 